\title{
Genetic effects of sterol regulatory element binding proteins and fatty acid-binding protein 4 on the fatty acid composition of Korean cattle (Hanwoo)
}

\author{
Dong-Yep $\mathrm{Oh}^{1, \mathrm{a}}$, Jea-Young Lee ${ }^{2, a}$, Ji-Eun Jang ${ }^{2}$, and Seung-Uk Lee ${ }^{3, *}$
}

\begin{abstract}
* Corresponding Author: Seung-Uk Lee Tel: +82-10-3811-1830, Fax: +82-54-638-6013, E-mail: ceels@nus.edu.sg
\end{abstract}

'Livestock Research institute, Yeongju 750-871, Korea 2 Department of Statistics, Yeungnam University, Gyeongsan 712-749, Korea

${ }^{3}$ Department of Civil and Environmental Engineering, National University of Singapore, Singapore 117576 Singapore

a These authors contributed equally to this work. Submitted Apr 4, 2016; Revised May 25, 2016; Accepted Aug 3, 2016
Objective: This study identifies single-nucleotide polymorphisms (SNP) or gene combinations that affect the flavor and quality of Korean cattle (Hanwoo) by using the SNP Harvester method. Methods: Four economic traits (oleic acid [C18:1], saturated fatty acids), monounsaturated fatty acids, and marbling score) were adjusted for environmental factors in order to focus solely on genetic effects. The SNP Harvester method was used to investigate gene combinations (two-way gene interactions) associated with these economic traits. Further, a multifactor dimensionality reduction method was used to identify superior genotypes in gene combinations. Results: Table 3 to 4 show the analysis results for differences between superior genotypes and others for selected major gene combinations using the multifactor dimensionality reduction method. Environmental factors were adjusted for in order to evaluate only the genetic effect. Table 5 shows the adjustment effect by comparing the accuracy before and after correction in two-way gene interactions.

Conclusion: The g.3977-325 T>C and (g.2988 A>G, g.3977-325 T>C) combinations of fatty acid-binding protein 4 were the superior gene, and the superior genotype combinations across all economic traits were the CC genotype at g.3977-325 T>C and the AACC, GACC, GGCC genotypes of (g.2988 A>G, g.3977-325 T>C).

Keywords: Fatty Acid-binding Protein4 (FABP4), Single-Nucleotide Polymorphism (SNP), SNP Harvester, Sterol Regulatory Element Binding Proteins (SREBPs), Hanwoo

\section{INTRODUCTION}

In recent years, Korea's food consumption has increasingly focused on food quality as a result of the public's favorable perception of well-being. Because meat generally requires high quality, many studies have focused on ways to produce high-quality meat. In general, consumers' preferences vary according to the taste and meatiness of beef, which are influenced by the fatty acid composition (FAC) and many other factors. Therefore, this study identifies the singlenucleotide polymorphisms (SNP) or gene combinations that influence the flavor and quality of Korean cattle (Hanwoo).

According to the literature, meatiness is determined by marbling score (MS), meat color, and texture, which are closely related to the tenderness, flavor, and juiciness of beef [1-3]. Among these, the flavor of beef is influenced by the content of its unsaturated fatty acids [4-6], and the oleic acid (C18:1) content of Hanwoo is particularly high in unsaturated fatty acids [7-9]. In addition, oleic acid accounts for more than $80 \%$ of the monounsaturated fatty acids (MUFAs) and is a key determinant of beef flavor [10,11]. Therefore, four traits (C18:1, saturated fatty acids [SFAs], MUFAs, and MS) have been found to be associated with the flavor 
and quality of Hanwoo. The routes for synthesizing fatty acids can be divided into two types. Many types of gene contribute to the synthesis of fatty acids. First, chylomicron and very-lowdensity lipoprotein produced in the small intestine and liver are transformed by the lipoprotein lipase $(L P L)$ gene in the form of fatty acids (Ed- you have not used this fatty acid [FA] acronym in most other places in the paper) $[12,13]$. Second, MalonylCoA, which is a substrate of the biosynthesis of fatty acids converted into 18:0-CoA by the fatty acid synthase (FASN) gene and the stearoyl-CoA desaturase (SCD) gene, converts stearic acid (C18:0) and palmitic acid (C16:0) into oleic acid (C18:1), which is an MUFA of the w-9 line $[11,14,15]$. In addition, a number of SNP combinations influencing the quality of Hanwoo have been found using the $S C D, F A S N$, and $L P L$ genes [16-18].

This study investigates how major gene combinations and genotypes using fatty acid-binding protein 4 (FABP4), which plays a major role in carrying fatty acids and which changes throughout two synthetic pathways in cells [19], and using sterol regulatory element binding proteins (SREBPs), which are transcriptional regulatory factors that influence the biosynthesis of fatty acids, affect the flavor of beef through its FAC and MS [20,21]. In addition, 8 genes (2 of SREBPs and 6 of $F A B P 4)$ were identified as superior to the remaining 23 genes (10 of SREBPS and 13 of FABP4) based on a test of FAC and economic traits [22]. In particular, as to the SNP selection on FABP4 (Genbank Accession No. NC_007312.4) and SREPBs (Genbank Number NC_007317.4), we have selected the 8 SNPs out of the total of 23 SNPs in our paper based on the result of the study [22] where only 8 SNPs showed polymorphism when 23 SNPs that showed base mutations across all intron and exon on genomic DNA were applied to the Hanwoo.

Environmental factors were adjusted first to examine only the genetic effects and verify the adjustment effects by comparing the accuracy before and after correction. Then, the SNP Harvester method was used to identify major gene combinations developed in Yang et al [23]. However, the SNP Harvester method was applied only to binary data in the case-control study. Therefore, this study's measures of the four traits were converted into binary values by using $\mathrm{k}$-means cluster analysis. Because genotypes for gene combinations could not be investigated using the SNP Harvester method, a multifactor dimensionality reduction method was employed to identify genotypes in gene combinations [24].

\section{MATERIALS AND METHODS}

\section{Animals and phenotypes}

Hanwoo cattle were bred in Gyeongbuk, Korea and 513 animals, the progeny of 18 sires, were used in this study. In general, they were weaned and castrated at 6 months of age, fed with growth stage feed for 18 months, and then fed a highly concentrated diet in their last 6 months. All steers were slaughtered at $941 \pm 72$ days of age, and MS was measured $24 \mathrm{~h}$ after slaughter.

Total lipids were extracted from approximately $500 \mathrm{mg}$ of m. longissimus dorsi muscle with chloroform/methanol (2:1, $\mathrm{v} / \mathrm{v}$ ) according to Folch et al [30]. Extracted lipids were then methylated based on O'Keefe et al [26] by using sodium methylate. The extract was then filtered through filter paper in a water bath $\left(40^{\circ} \mathrm{C}\right)$. The filtrate was mixed with distilled water, and then a layer of methanol and water was removed. After the removal of chloroform and lipid layers using nitrogen gas, the sample was treated with BF3-methanol (14\%) and subjected to trans-methylation at $65^{\circ} \mathrm{C}$. Fatty acid content was analyzed using gas-chromatography (PerkinElmer, Inc., Waltham, MA, USA).

\section{Genomic DNA and SNP genotyping}

Total genomic DNA was extracted from the longissimus muscle using the LaboPass TM Tissue Mini kit (Cosmo Genetech, Seoul, Korea). Two polymorphic SNPs of SREBPs and six polymorphic SNPs of the FABP4 gene in GenBank were genotyped according to $\mathrm{Oh}$ et al [27]. Primers for amplifications and extensions were designed for the single-base extension (Ed- this acronym is not used anywhere in the paper) for genotyping polymorphic sites [33] using forward, reverse, and extension primer sequences [27]. Reactions of the primer extension were performed using the SNaPshotddNTP Primer Extension Kit (Applied Biosystems, Foster City, CA, USA). One unit of shrimp alkaline phosphatase was added to the reaction mixture, which was then incubated for $1 \mathrm{~h}$ at $37^{\circ} \mathrm{C}$, followed by $15 \mathrm{~min}$ at $72^{\circ} \mathrm{C}$ for enzyme inactivation, to clean the primer extension reaction. DNA samples containing extension products and the Gene-scan 120 LIZ size standard solution were added to Hi-Di formamide (Applied Biosystems, USA) in accordance with the manufacturer's recommendations. The mixture was incubated for $5 \mathrm{~min}$ at $95^{\circ} \mathrm{C}$, followed by $5 \mathrm{~min}$ on ice, after which electrophoresis was conducted using the ABI PRISM 3130XL GeneticAnalyzer. The analysis was made using GeneMapper v4.0 (Applied Biosystems, USA).

\section{Adjust model and Statistical analysis}

Genetic factors influencing the economic traits associated with the flavor and quality of Hanwoo were examined. These economic traits included the breeding farm and age as environmental factors, and SNPs as a genetic factor [29]. To identify the genetic factors influencing economic traits, a model adjusted for environmental factors such as the breeding farm and age was used:

$$
\begin{aligned}
y_{k}= & \mu+\alpha_{0}\left(\text { age }_{k}-\overline{\operatorname{age}}\right)+\alpha_{1} \text { farm }_{1 k}+\cdots \\
& +\alpha_{l-1} \text { farm }_{l-1, k}+\beta_{1} S N P_{1 k}+\cdots+\beta_{m} S N P_{m k}+\varepsilon_{k} \\
& \mathrm{i}=1,2, \cdots \mathrm{l} ; \mathrm{j}=1,2, \cdots, \mathrm{m} ; \mathrm{k}=1,2, \cdots, \mathrm{n}
\end{aligned}
$$


Where $y_{k}$ is a phenotype, $\mu$ the overall mean of each trait, agek the age of the $k$ th Hanwoo, $\overline{a g e}$ the overall mean age, $\alpha_{0}$ a regression coefficient for age, farm $_{i k}$ the fixed effect of the $k$ th Hanwoo and the $i$ th breeding farm, $\alpha_{i}$ a regression coefficient for the breeding farm, $S N P_{j k}$ the fixed effect of the $k$ th Hanwoo and the jth SNP, and $\varepsilon_{k}$ a random residual assumed to have an independent and identical normal distribution.

A simple form of the above equation is

$$
\mathrm{Y}=\mu+\mathrm{E} \alpha+\mathrm{G} \beta+\varepsilon
$$

Where $\mu$ is the total mean vector, Ea the environmental effect ( $\mathrm{E}$ is an explanatory variable matrix including the environmental factor, and $\alpha$ is a regression coefficient vector representing the effect of environmental factors), and $G \beta$ the genetic effect ( $G$ is an explanatory variable matrix including the genetic factor, and $\beta$ is a regression coefficient vector representing the effect of genetic factors).

The effects $\hat{\alpha}$ of environmental factors such as age and the breeding farm were examined using the above model, and the economic trait $\mathrm{Z}$ was determined for a pure genetic factor to compensate for the effects of environmental factors on estimates. Here the equation was

$\mathrm{Z}=\mathrm{Y}-\mathrm{E} \hat{\alpha}$

Where $\mathrm{Z}$ is an adjusted value which eliminates the environ- mental factors. In this study, we use $\mathrm{Z}$ as a pure genetic factor for statistical analysis.

\section{SNP harvester}

The SNP harvester method can be used to identify major genotype combinations associated with human diseases and economic traits of livestock [23]. This method selects several SNPs linked to economic traits as combinations and then repeats the process to increase scores by changing one of the unchosen SNP-to-SNP combinations. The score function can use the $x^{2}$ statistic, classification accuracy, and the B-statistic. In this study, the $x^{2}$ statistic with $3^{k}-1$ degrees of freedom was used. The procedure was as follows (Figure 1):

Step 1. Randomly select $k$ groups from all SNP groups and assign group names (e.g., group A). Then set the rest of SNPs as $S N P_{i}$

Step 2. Exchange $S N P_{i}$ that do not belong to group A with group A elements on a one-by-one basis to calculate scores:

$$
\begin{aligned}
& A_{1}=\left(S N P_{S 1}, S N P_{S 2}, \ldots, S N P_{i}\right) \Rightarrow \text { Score } A_{1} \\
& A_{2}=\left(S N P_{S 1}, S N P_{i}, \ldots, S N P_{k}\right) \Rightarrow \operatorname{Score} A_{2} \\
& \ldots \\
& A_{k}=\left(S N P_{i}, S N P_{S 2}, \ldots, S N P_{k}\right) \Rightarrow \text { Score } A_{k}
\end{aligned}
$$

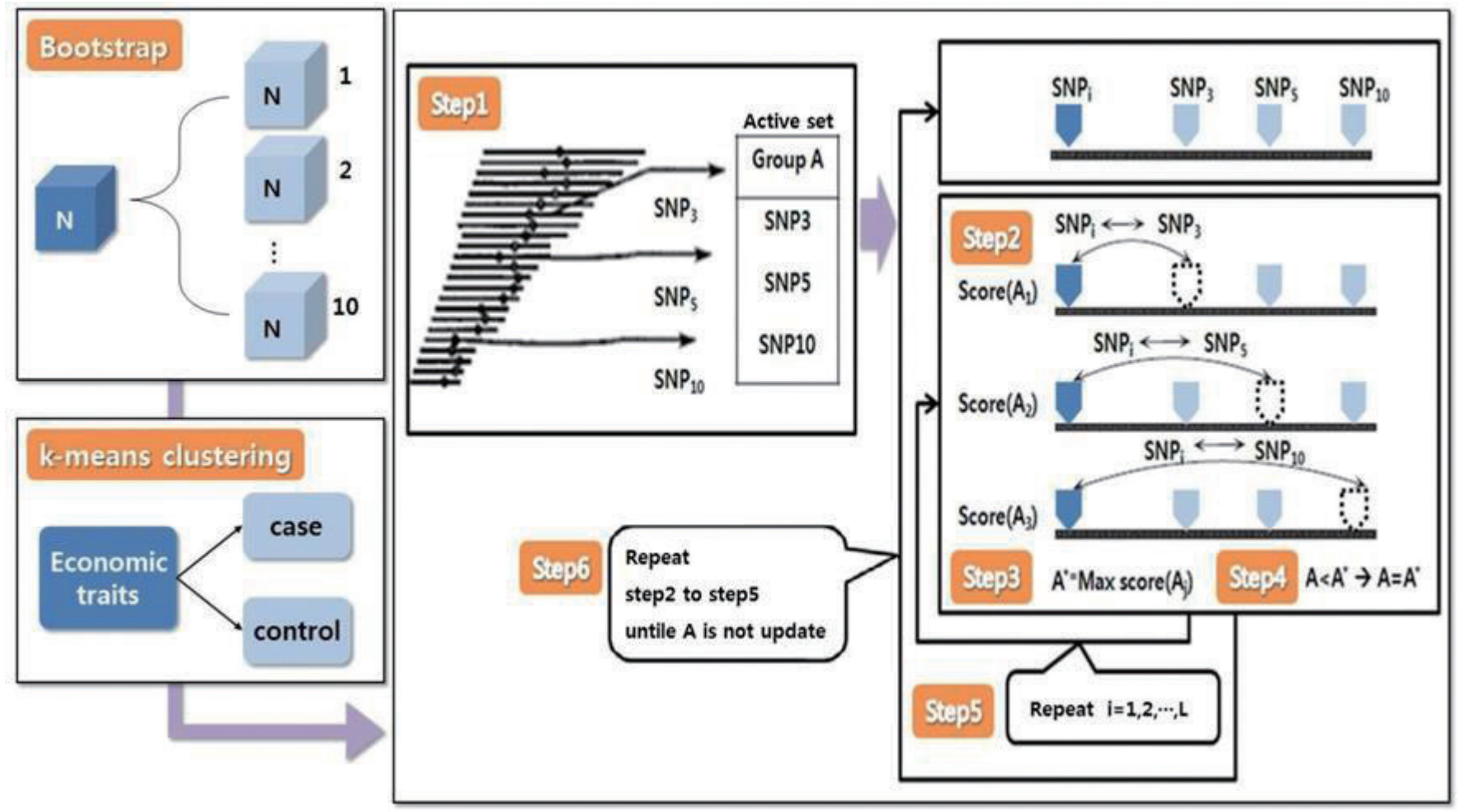

Figure 1. The single-nucleotide polymorphisms Harvester procedure [28]. 
Step 3. Set the highest value from Step 2 as $A^{*}$.

Step 4. If $A^{*}$ has a higher score than $A$, then replace $A$ with $A^{*}$.

Step 5. If the score of $A^{*}$ exceeds the threshold, then $A *$ is classified as a significant group.

Step 6. For $S N P_{i+1}$ that does not belong to group A, repeat Steps 2-5.

Step 7. If $\mathrm{A}^{*}$ is not replaced with any other $S N P_{i+1}$, then the process is stopped, and $A^{*}$ is determined as the final SNP combination set.

By repeating these steps, SNP combinations influencing economic traits were selected. The SNP Harvester method was applied only to binary data in the case-control study. Therefore, measures of economic traits were converted into binary values through $\mathrm{k}$-means cluster analysis.

\section{RESULTS AND DISCUSSION}

In this study, the SNPs associated with the FAC and quality of Hanwoo were FABP4 (g.2634+1018 A>T, g.2988 A>G, g.3690 G>A, g.3710 G>C, g.3977-325 T>c, and g.4221 A $>$ G) and SREBPs (g.3270+10274 C>T and g.13544 T>C). In addition, the four economic traits (C18:1, SFAs, MUFAs, and MS) that affect the evaluation criteria for Hanwoo, particularly the flavor and meatiness of beef, were considered. In addition, environmental factors such as age and the breeding farm were adjusted by linear regression analysis to evaluate only the genetic effect. Data were from 5,130 bootstrap samples based on the 513 steers in Oh et al [22]. The SNP Harvester method was used to find major gene combinations, and then a multifactor dimensionality reduction method was used to identify superior genotypes in gene combinations. Finally, the superior gene or SNP combination was identified by comparing individual and interaction effects.

Table 1 and 2 show the upper seven SNP combinations of two-way gene interactions related to the four economic traits.
Table 2. Upper seven-SNP combinations based on two-way gene interactions for MS

\begin{tabular}{|c|c|c|}
\hline SNP interaction & $x^{2}$ (p-value) & Cohen's w $w^{2)}$ \\
\hline g.3690 G > A, g.3977-325 T>C1) & $\begin{array}{l}2,213.03 \\
(<0.0001)\end{array}$ & 0.66 \\
\hline g.3270+10274 C>T, g.3977-325 T>C') & $\begin{array}{l}1,024.47 \\
(<0.0001)\end{array}$ & 0.45 \\
\hline g.2634+1018 A>T, g.3690 G>A ${ }^{1)}$ & $\begin{array}{c}993.31 \\
(<0.0001)\end{array}$ & 0.44 \\
\hline g. $3270+10274 C>T, g .3690 \mathrm{G}>A$ & $\begin{array}{c}810.19 \\
(<0.0001)\end{array}$ & 0.40 \\
\hline g.3270+10274 C> T, g.2634+1018 A > T & $\begin{array}{c}577.58 \\
(<0.0001)\end{array}$ & 0.34 \\
\hline g.3270+10274 C > T, g.13544 T>C & $\begin{array}{c}314.75 \\
(<0.0001)\end{array}$ & 0.25 \\
\hline g. $13544 \mathrm{~T}>\mathrm{C}, \mathrm{g} .3710 \mathrm{G}>\mathrm{C}$ & $\begin{array}{c}288.06 \\
(<0.0001)\end{array}$ & 0.24 \\
\hline
\end{tabular}

SNP, single-nucleotide polymorphism; MS, marbling score.

${ }^{1)}$ Major gene combination. ${ }^{2)}$ Cohen's effect size.

The value of $x^{2}$ statistic used in SNP Harvester method, p-value and Cohen's w were indicated. The effect size, w, was used by Cohen (1988) [30]. They set a small value of $w$ at 0.1, a medium value at 0.3 , and a large value at 0.5 [29]. Because most of the values shown in the Table 1, 2 appears larger than the medium value of 0.3 , result can be seen to be effective. For the economic traits (C18:1, SFAs, and MUFAs) associated with fatty acids (Table 1), (g.3270+10274 C>T g.13544 T>C), (g.3270+10274 C>T, g.2634+1018 A>T), (g.2988 A>G, g.3977-325 T>C), and (g.3977-325 T>C, g.4221 A>G) were chosen as major gene combinations. For MS (Table 2), the upper three combinations (g.3690 G>A, g.3977-325 T>C), (g.3270+10274 C>T, g.3977$325 \mathrm{~T}>\mathrm{C}$ ), and (g.2634+1018 A>T, g.3690 G>A) were selected as major gene combinations.

Table 3 and 4 show the analysis results for differences between superior genotypes and others for selected major gene combinations using the multifactor dimensionality reduction method.

Table 1. Upper seven-SNP combinations based on two-way gene interactions for each fatty acid

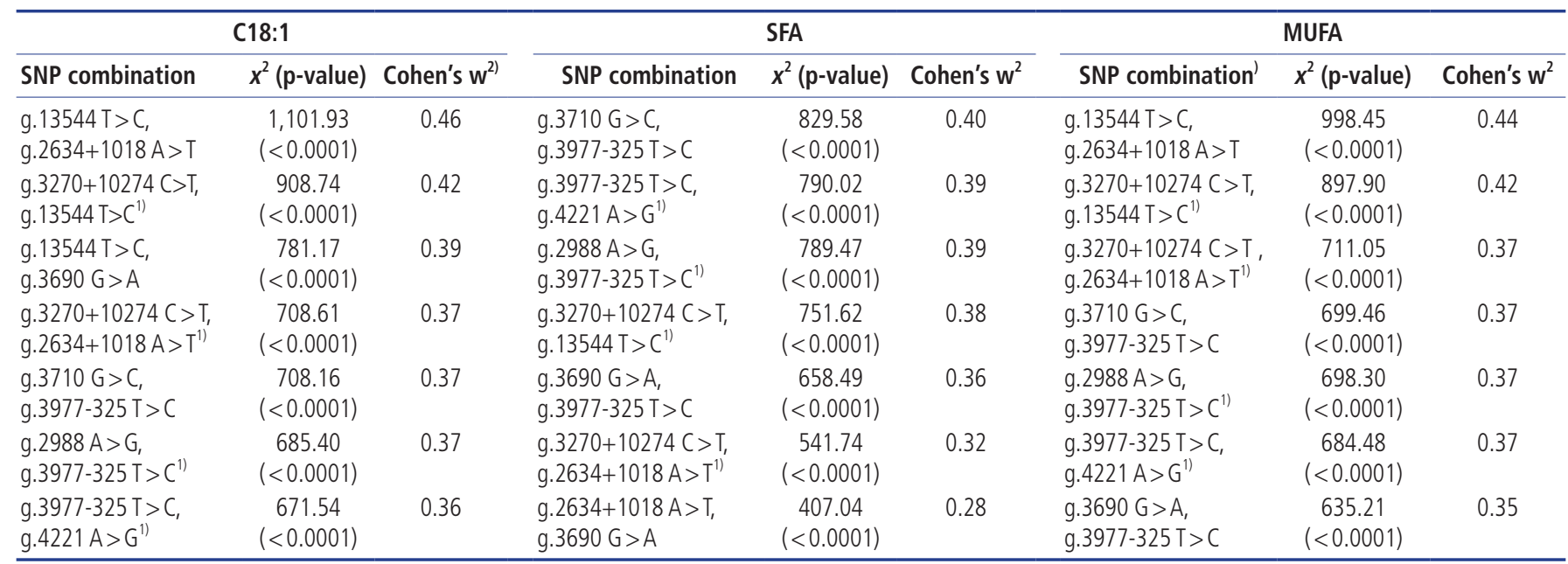

SNP, single-nucleotide polymorphism; SFA, saturated fatty acid; MUFA, monounsaturated fatty acids.

${ }^{1)}$ Major gene combination. ${ }^{2)}$ Cohen's effect size. 
Table 3. Superior genotypes of four-SNP combinations selected by fatty acids

\begin{tabular}{|c|c|c|c|c|c|c|}
\hline SNP combination & Traits & Genotype & $\mathrm{N}$ & Mean & SD & $t$ (p-value) \\
\hline \multirow{6}{*}{$\begin{array}{l}\text { g. } 3270+10274 C>T \\
\text { g. } 13544 \mathrm{~T}>C\end{array}$} & \multirow[t]{2}{*}{ C18:1 } & TTTT, CTTT, CCTT, TTCT, CTCT, TTCC & 2,390 & 44.89 & 1.50 & \multirow[t]{2}{*}{$<0.0001$} \\
\hline & & Others & 2,740 & 43.17 & 0.96 & \\
\hline & \multirow[t]{2}{*}{ SFA } & TTTT, CTTT, TTCT, СTCT & 1,320 & 40.60 & 1.15 & \multirow[t]{2}{*}{$<0.0001$} \\
\hline & & Others & 3,810 & 42.14 & 0.89 & \\
\hline & \multirow[t]{2}{*}{ MUFA } & TTTT, CTTT, ТTCT, CTCT, TTCC & 2,358 & 53.76 & 1.55 & \multirow[t]{2}{*}{$<0.0001$} \\
\hline & & Others & 2,772 & 51.97 & 0.99 & \\
\hline \multirow{4}{*}{$\begin{array}{l}\text { g. } 3270+10274 C>T, \\
\text { g.2634+1018 A }>T\end{array}$} & \multirow[t]{2}{*}{ SFA } & TTAA, CTAA & 2,540 & 41.17 & 1.25 & \multirow[t]{2}{*}{$<0.0001$} \\
\hline & & Others & 2,590 & 42.31 & 0.76 & \\
\hline & \multirow[t]{2}{*}{ MUFA } & TTAA, CTAA & 2,540 & 53.64 & 1.61 & \multirow[t]{2}{*}{$<0.0001$} \\
\hline & & Others & 2,590 & 51.96 & 0.94 & \\
\hline \multirow{2}{*}{$\begin{array}{l}\text { g.2988 A>G, } \\
\text { g.3977-325 T> (1) }\end{array}$} & C18:1 & AACC, GACC, GGCC2) & 830 & 46.69 & 0.90 & $<0.0001$ \\
\hline & MUFA & Others & 4,300 & 52.24 & 0.92 & $<0.0001$ \\
\hline \multirow{6}{*}{$\begin{array}{l}\text { g.3977-325 T>C, } \\
\text { g. } 4221 \mathrm{~A}>\mathrm{G}\end{array}$} & \multirow[t]{2}{*}{ C18:1 } & CCAA, CCGA, CCGG & 830 & 46.69 & 0.90 & \multirow[t]{2}{*}{$<0.0001$} \\
\hline & & Others & 4,300 & 43.45 & 0.92 & \\
\hline & \multirow[t]{2}{*}{ SFA } & TTGG, CCAA, CCGA, CCGG & 1,094 & 40.02 & 1.07 & \multirow[t]{2}{*}{$<0.0001$} \\
\hline & & Others & 4,036 & 42.21 & 0.65 & \\
\hline & \multirow[t]{2}{*}{ MUFA } & CCAA, CCGA, CCGG & 830 & 55.65 & 0.96 & \multirow[t]{2}{*}{$<0.0001$} \\
\hline & & Others & 4,300 & 52.24 & 0.92 & \\
\hline
\end{tabular}

SNP, single-nucleotide polymorphism; SD, standard deviation; SFA, saturated fatty acid; MUFA, monounsaturated fatty acids.

${ }^{1)}$ The best gene combination. ${ }^{2)}$ Superior genotype of the best combination.

For C18:1 and MUFAs, an increase in their content increases the quality of Hanwoo $[8,10]$, whereas the opposite trend arises for SFAs [22]. In all gene combinations, differences between superior genotypes and others were significant. In addition, (g.2988 A>G, g.3977-325 T>C) and (g.3690 G>A, g.3977-325 $\mathrm{T}>\mathrm{C}$ ) were selected as the best combinations with the largest difference in traits associated with fatty acids (C18:1, SFAs, and MUFAs) and MS, respectively $(\mathrm{p}<0.0001)$.

Environmental factors were adjusted for in order to evaluate only the genetic effect. Table 5 shows the adjustment effect by comparing the accuracy before and after correction in two-way gene interactions. There were increases in accuracy in all gene combinations. In addition, (g.2988 A>G, g.3977-325 T>C) and (g.3690 G>A, g.3977-325 T>C), which were selected as the best combinations, showed the largest increases. After adjustment, training- and testing-balanced accuracy values for (g.2988 A $>\mathrm{G}$, g.3977-325 T>C) were 0.9210 and 0.9163, respectively, for C18:1; 0.9329 and 0.9329 , respectively, for SFAs; and 0.9314 and 0.9314 , respectively, for MUFA. Further, training- and testing-balanced accuracy values for (g.3690 G>A, g.3977-325 T>C) were 0.9143 and 0.9143 , respectively, for MS. Table 6 compares the individual and interaction effects of the best combination. For all economic traits, g.3977-325 T>C was the superior gene, and CC of g.3977$325 \mathrm{~T}>\mathrm{C}$ was the superior genotype. For C18:1 and MUFAs, the g.3977-325 T>C and (g.2988 A>G, g.3977-325 T>C) combinations had the same effect.

In conclusions, g.3977-325 T>C and (g.2988 A>G, g.3977$325 \mathrm{~T}>\mathrm{C}$ ) combinations of FABP4 were the superior SNP, particularly combinations of the CC genotype of g.3977-325 $\mathrm{T}>\mathrm{C}$ and the AACC, GACC, GGCC genotypes of (g.2988 A>G,

Table 4. Superior genotypes of three-SNP combinations selected by MS

\begin{tabular}{|c|c|c|c|c|c|}
\hline SNP combination & Genotype & $\mathrm{N}$ & Mean & SD & $t$ (p-value) \\
\hline \multirow[t]{2}{*}{ g.3690 G>A, g.3977-325 T>C (1) } & GGCT, GGCC, GACC ${ }^{2)}$ & 2,194 & 6.35 & 0.54 & $<0.0001$ \\
\hline & Others & 2,936 & 5.38 & 0.37 & \\
\hline \multirow[t]{2}{*}{ g. $3270+10274 C>T$, g.3977-325 T>C } & TTCT, TTCC, CTCT, CTCC, CCCC & 2,578 & 6.23 & 0.57 & $<0.0001$ \\
\hline & Others & 2,552 & 5.35 & 0.39 & \\
\hline \multirow[t]{2}{*}{ g.2634+1018 A > T, g.3690 G>A } & AAGG & 1,936 & 6.18 & 0.66 & $<0.0001$ \\
\hline & Others & 3,194 & 5.56 & 0.54 & \\
\hline
\end{tabular}

SNP, single-nucleotide polymorphism; SD, standard deviation; MS, marbling score.

${ }^{1)}$ The best gene combination. ${ }^{2)}$ Superior genotype of the best combination. 
Table 5. Adjustment effect by comparing accuracy before and after correction in two-SNP combinations

\begin{tabular}{|c|c|c|c|c|c|}
\hline \multirow{2}{*}{ Traits } & \multirow{2}{*}{ SNP combination } & \multicolumn{2}{|c|}{ Training-bal. accuracy ${ }^{2)}$} & \multicolumn{2}{|c|}{ Testing-bal. accuracy ${ }^{3)}$} \\
\hline & & Before & After & Before & After \\
\hline \multirow[t]{3}{*}{ C18:1 } & g.3270+10274 C>T, g.13544 T>C & 0.6742 & 0.7211 & 0.6742 & 0.7174 \\
\hline & g.2988 A > G, g.3977-325 T> C1) & 0.6288 & 0.9210 & 0.6288 & 0.9163 \\
\hline & g.3977-325 T>C, g.4221 A > G & 0.6337 & 0.9208 & 0.6337 & 0.9208 \\
\hline \multirow[t]{2}{*}{ SFA } & g.3270+10274 C>T, g.13544 T>C & 0.5965 & 0.7100 & 0.5965 & 0.7100 \\
\hline & g. $3977-325$ T >C, g. $4221 \mathrm{~A}>\mathrm{G}$ & 0.6135 & 0.9307 & 0.6135 & 0.9307 \\
\hline \multirow[t]{4}{*}{ MUFA } & g. $3270+10274 C>T$, g. $13544 \mathrm{~T}>\mathrm{C}$ & 0.6314 & 0.7166 & 0.6314 & 0.7127 \\
\hline & g. $3270+10274 C>T, g .2634+1018 \mathrm{~A}>\mathrm{T}$ & 0.6507 & 0.7625 & 0.6507 & 0.7625 \\
\hline & g.2988 A > G, g.3977-325 T> (1) & 0.6489 & 0.9314 & 0.6489 & 0.9314 \\
\hline & g.3977-325 T>C, g.4221 A>G & 0.6540 & 0.9314 & 0.6540 & 0.9314 \\
\hline
\end{tabular}

SNP, single-nucleotide polymorphism; SFA, saturated fatty acid; MUFA, monounsaturated fatty acids; MS, marbling score.

${ }^{1)}$ It is the best gene combination and shows the largest increases in each economic trait.

${ }^{2)}$ Training-balanced accuracy. ${ }^{3)}$ Testing-balanced accuracy.

g.3977-325 T>C). Consequently, future research should focus on this gene to produce high-quality beef that is low in SFAs and high in MUFAs and MS for the further development of the Hanwoo industry.

\section{CONFLICT OF INTEREST}

We certify that there is no conflict of interest with any financial organization regarding the material discussed in the manuscript.

Table 6. A comparison of individual and two-SNP interaction effects on fatty acids and MS

\begin{tabular}{|c|c|c|c|c|c|c|}
\hline Traits & SNP & Genotype & $\mathrm{N}$ & Mean & SD & $t$ (p-value) \\
\hline \multirow[t]{6}{*}{ C18:1 } & \multirow[t]{2}{*}{ g. $2988 A>G$} & GG & 770 & 44.77 & 1.66 & \multirow[t]{2}{*}{$<0.0001$} \\
\hline & & Others & 4,360 & 43.83 & 1.43 & \\
\hline & \multirow[t]{2}{*}{ g. $3977-325 T>C^{1)}$} & $\left(C^{2)}\right.$ & 830 & 46.69 & 0.90 & \multirow[t]{2}{*}{$<0.0001$} \\
\hline & & Others & 4,300 & 43.45 & 0.91 & \\
\hline & \multirow[t]{2}{*}{ g.2988 A > G, g.3977-325 T>C $C^{1)}$} & $\mathrm{AACC}, \mathrm{GACC}, \mathrm{GGCC}{ }^{2)}$ & 830 & 46.69 & 0.90 & \multirow[t]{2}{*}{$<0.0001$} \\
\hline & & Others & 4,300 & 43.45 & 0.92 & \\
\hline \multirow[t]{6}{*}{ SFA } & \multirow[t]{2}{*}{ g. 2988 A > G } & GG & 770 & 41.13 & 1.26 & \multirow[t]{2}{*}{$<0.0001$} \\
\hline & & Others & 4,360 & 41.85 & 1.13 & \\
\hline & \multirow[t]{2}{*}{ g. $3977-325 T>C^{1)}$} & $\mathrm{CC} 2$ & 830 & 39.55 & 0.63 & \multirow[t]{2}{*}{$<0.0001$} \\
\hline & & Others & 4,300 & 42.17 & 0.68 & \\
\hline & \multirow[t]{2}{*}{ g.2988 A > G, g.3977-325 T>C } & GGTT, AACC, GACC, GGCC & 1,076 & 39.99 & 1.05 & \multirow[t]{2}{*}{$<0.0001$} \\
\hline & & Others & 4,054 & 42.21 & 0.65 & \\
\hline \multirow[t]{6}{*}{ MUFA } & \multirow[t]{2}{*}{ g. 2988 A > G } & GG & 770 & 53.71 & 1.67 & \multirow[t]{2}{*}{$<0.0001$} \\
\hline & & Others & 4,360 & 52.63 & 1.48 & \\
\hline & \multirow[t]{2}{*}{ g.3977-325 T > (1) } & $\mathrm{CC} 2$ & 830 & 55.65 & 0.96 & \multirow[t]{2}{*}{$<0.0001$} \\
\hline & & Others & 4,300 & 52.24 & 0.92 & \\
\hline & \multirow[t]{2}{*}{ g.2988 A > G, g.3977-325 T>C $C^{1)}$} & $\mathrm{AACC}, \mathrm{GACC}, \mathrm{GGCC} \mathrm{C}^{2)}$ & 830 & 55.65 & 0.96 & \multirow[t]{2}{*}{$<0.0001$} \\
\hline & & Others & 4,300 & 52.24 & 0.92 & \\
\hline \multirow[t]{6}{*}{ MS } & \multirow[t]{2}{*}{ g. $3690 \mathrm{G}>\mathrm{A}$} & GG & 2,853 & 6.00 & 0.6491 & \multirow[t]{2}{*}{$<0.0001$} \\
\hline & & Others & 2,277 & 5.53 & 0.5704 & \\
\hline & \multirow[t]{2}{*}{ g. $3977-325 T>C^{1)}$} & $\mathrm{CC} 2$ & 830 & 6.81 & 0.4480 & \multirow[t]{2}{*}{$<0.0001$} \\
\hline & & Others & 4,300 & 5.60 & 0.4880 & \\
\hline & \multirow[t]{2}{*}{ g.3690 G>A, g.3977-325 T>C } & GGCT, GGCC, GACC & 2,194 & 6.35 & 0.5356 & \multirow[t]{2}{*}{$<0.0001$} \\
\hline & & Others & 2,936 & 5.38 & 0.3742 & \\
\hline
\end{tabular}

SNP, single-nucleotide polymorphism; MS, marbling score; SD, standard deviation; SFA, saturated fatty acid; MUFA, monounsaturated fatty acids.

${ }^{1)}$ The best gene or gene combination. ${ }^{2)}$ Superior genotype of the best gene or gene combination. 


\section{REFERENCES}

1.Van der Wal PG, Engel B, Hulsegge B. Causes for variation in pork quality. Meat Sci 1997;46:319-22.

2.Robins K, Jensen J, Ryan KJ, et al. Consumer attitude towards beef and acceptability of enhanced beef. Meat Sci 2003;65:721-9.

3.Monsón F, Sañudo C, Sierra I. Influence of breed and ageing time on sensory meat quality and consumer acceptability in intensively reared beef. Meat Sci 2005;71:471-9.

4.Melton SL, Amiri M, Davis GW, Backus WR. Flavor and chemical characteristics of ground beef from grass-, forage-grain and grainfinished steers. Anim Sci J 1982;55:77-87.

5.Sturdivant CA, Lunt DK, Smith GC, Smith SB. Fatty acid composition of subcutaneous and intramuscular adipose tissues and $\mathrm{M}$. longissimus dorsi of Wagyu cattle. Meat Sci 1991;32:449-58.

6.Jeremiah LE. The influence of subcutaneous fat thickness and marbling on beef. Food Res Int 1996;29:513-20.

7.May SG, Sturdivant CA, Lunt DK, Miller RK, Smith SB. Comparison of sensory characteristics and fatty acid composition between wagyu crossbred and Angus steers. Meat Sci 1993;35:289-98.

8.Oka A, Iwaki F, Dohgo T, et al. Genetic effects on fatty acid composition of carcass fat of Japanese Black Wagyu steers. Anim Sci J 2002;80:1005-11.

9.Chung KY, Lunt DK, Kawachi H, Yano H, Smith SB. Lipogenesis and stearoyl-CoA desaturase gene expression and enzyme activity in adipose tissue of short- and long-fed Angus and Wagyu steers fed corn- or hay-based diets. J Anim Sci 2007;85:380-7.

10. Yosimura T, Namikawa K. Influence of breed, sex and anatomical location on lipid and fatty acid composition of bovine subcutaneous fat. Jpn J Zootech Sci 1983;54:97-100.

11. Taniguchi M, Utsugi T, Oyama K, et al. Genotype of stearoyl - CoA desaturase is associated with fatty acid composition in Japanese Black cattle. Mamm Genome 2004;14:142-8.

12. Havel R, Shore V, Bier D. Role of specific peptides of serum liporoteins in the action of lipoprotein lipase. Circl 1970;41:111-6.

13. Gotoda T, Yamada N, Kawamura M, et al. Heterogeneous mutations in the human lipoprotein lipase gene in patients with familial lipoprotein lipase deficiency. J Clin Invest 1991;88:1856-64.

14. Barton L, Kott T, Bures D, et al. The polymorphism of stearoylCoA desaturase (SCD1) and sterol regulatory element binding proyein-1 (SREBP-1) genes and their association with the fatty acid profile of muscle and subcutaneous fat in Fleckvieh bulls. Meat Sci 2010;85:15-20.

15. Ohsaki H, Tanaka A, Hoashi S, et al. Effect of SCD and SREBP genotypes on fatty acid composition in adipose tissue of Japanese Black cattle herds. Anim Sci J 2009;80:225-32.

16. Jin MH, Oh DY, Lee JY. Major gene identification for LPL gene in
Korean cattles. J Korean Data Inf Sci Soc 2013;24:1331-9.

17. Oh DY, Jin MH, Lee YS, et al. Identification of stearoyl-coa desaturase (SCD) gene interactions in Korean Native cattle based on the multifactor-dimensionality reduction method. Asian-Australas J Anim Sci 2013;26:1218-28.

18. Lee J, Jin M, Lee Y, et al. Gene-gene interactions of fatty acid synthase (FASN) using multifactor-dimensionality reduction method in Korean cattle. Mol Biol Rep 2014;41:2021-7.

19. Chmurzyńska A.The multigene family of fatty acid-binding proteins (FABPs): function, structure and polymorphism. J Appl Genet 2006;47:39-48.

20. Hoashi S, Ashida N, Ohsaki H, et al. Genotype of bovine sterol regulatory element binding protein-1(SREBP-1) is associated with fatty acid composition in Japanese Black cattle. Mamm Genome 2007;18:880-6.

21. Oh D, Lee Y, Lee C, Chung E, Yeo J. Association of bovine fatty acid composition with missense necleotide polymorphism in exon7 of peroxisome proliferator-activated receptor gamma gene. Anim Genet 2012;43:474-481.

22. Oh DY. Identification of the SNP (single nucleotide polymorphism) within candidate gene associated with fatty composition in Hanwoo [dissertation]. Kyungsan, KR: Yeungnam University; 2014.

23. Yang C, He Z, Wan X, et al. SNP Harvester a filtering-based approach for detecting epistatic interactions in genome-wide association studies. Bioinformatics 2009;25:504-11.

24. Hahn LW, Ritchie MD, Moore JH. Multifactor dimensionality reduction software for detecting gene-gene and gene-environment interactions. Bioinformatics 2003;19:376-82.

25. Folch J, Lees M, Sloane Stanley GH. A simple method for the isolation and purification of 12 total lipids from animal tissue. J Biol Chem 1957;226:497-509.

26. O'Keefe PW, Wellington GH, Mattick LR, Stouffer JR. Composition of bovine muscle lipids at various carcass locations. J Food Sci 1968;33:188-92.

27. Oh D, Lee Y, La B, et al. Fatty acid composition of beef is associated with exonic nucleotide variants of the gene encoding FASN. Mol Biol Rep 2012;39:4083-90.

28. Vreeland WN, Meagher RJ, Barron AE. Multiplexed, highthroughput genotype by single_base extension and endlabeled free_solution electrophoresis. Anal Chem 2002;74:4328-33.

29. Matsuhashi T, Maruyama S, Uemoto Y, et al. Effect of bovine fatty acid synthase, stearoyl-coenzyme a desaturase, sterol regulatory element-binding protein 1 , and growth hormone gene polymorphisms on fatty acid composition and carcass traits in Japanese Black cattle. J Anim Sci 2011;89:12-22.

30. Cohen J. Statistical power analysis for the behavioral sciences. 2th ed. Hillsdale, NJ: Lawrence Erlbaum Associates; 1998 